\title{
Uncertainty Measurement of Closed Flash Point of Organic Heat Carrier
}

\author{
Yan Rong ${ }^{1, a}$, Linyuan $\mathrm{Guo}^{2}$, Yunyan Peng ${ }^{3}$, Jianhua Yang ${ }^{4}$, and Dong Jin ${ }^{1}$ \\ ${ }^{1}$ China Special Equipment Inspection and Research Institute, Beijing \\ ${ }^{2}$ China Special Equipment Inspection and Research Institute, Beijing \\ ${ }^{3}$ China Special Equipment Inspection and Research Institute, Beijing \\ ${ }^{4}$ China Special Equipment Inspection and Research Institute, Beijing
}

\begin{abstract}
The closed flash point is an important indicator in the detection of organic heat carrier. In this paper, based on the Pensky-Martin flash point (closed) measurement method, the closed flash point of the organic heat carrier is measured with an automatic closed cup flash point meter. The factors that may affect the accuracy of the measurement result during the measurement process are analyzed, and the uncertainty is determined. Through the analysis of the established uncertainty component sources, the repeatability measurement of the organic heat carrier, the temperature sensor, the pressure sensor, and the numerical rounding based on the standard, the results of the closed flash point determination of the organic heat carrier are obtained. The synthetic uncertainty and the relative expanded uncertainty are evaluated to improve the reliability of the measurement results of the closed flash point of the organic heat carrier and provide a reference for the quality control of the organic heat carrier.
\end{abstract}

\section{Introduction}

With more and more attention paid to energy saving and environmental protection, organic heat carrier, as an excellent heat transfer medium, has the advantages of high temperature and low pressure heat transfer performance, high thermal efficiency, good heat transfer effect, accurate temperature control, low operation cost, energy saving and so on [1]. It has been widely used in petroleum transportation, petrochemical industry, synthetic fiber, synthetic resin, textile printing and dyeing Food processing, pharmaceutical synthesis, building materials, energy, transportation and other industries [2-3].

The lower the flash point is, the higher the evaporation rate of heat transfer oil is, and the worse the safety is [46],Heat transfer oil with higher flash point has better operation safety and thermal stability.

This paper mainly studies the uncertainty measurement of closed flash point of organic heat carrier. Through calculation, it can determine the closed flash point of organic heat carrier better, and ensure the safety of operation.

The flash point is the lowest temperature at which the material or product will flash and burn immediately when it comes into contact with the flame when it forms a mixture with the outside air [7]. The measurement methods of flash point include open flash point and closed flash point.In this paper, according to the GB/T 261-2008 Binskin-Martin closed cup method ,the closed flash point of the organic heat carrier sample was determined and the uncertainty measurement was evaluated [8].

\section{Experiment}

\subsection{Measurement methods and overview}

\subsubsection{Samples and equipment}

L-QB 300 organic heat carrier

PMA 5 Automatic Closed Flashpoint Tester (Antonpa Company, Austria)

\subsubsection{The experimental method}

Method A in GB/T 261-2008 Binski-Martin Closed Cup Method for Determination of Flash Point was used in this experiment. Place the sample in a closed cup, stir continuously at a specified rate, and heat the sample at a constant rate. At every $1{ }^{\circ} \mathrm{C}$ temperature interval, the ignition source was flashed across the sample surface, and the sample vapor ignited and spread to the lowest temperature on the liquid surface. This temperature was recorded as the flash point of the sample (closed port), and then corrected to the flash point at $101.3 \mathrm{kPa}$ atmospheric pressure.

The correction formula of closed flash point is as follows:

$$
\mathrm{Tc}=\mathrm{T} 0+0.25(101.3-\mathrm{P})
$$

Tc -- closed flash point at standard atmospheric pressure; ${ }^{\circ} \mathrm{C}$

*Corresponding author's e-mail: hxfxzx2017@126.com 
To -- the observed flash point at ambient atmospheric pressure; ${ }^{\circ} \mathrm{C}$

$\mathrm{P}$-- ambient atmospheric pressure; $\mathrm{KPa}$

\subsection{Determine the source of uncertainty}

The uncertainty of closed flash point of the organic heat carrier mainly comes from the following aspects :(1) the uncertainty component $U_{1}$ introduced by repeated measurement of the sample; (2) The uncertainty caused by the temperature sensor of the instrument is $U_{2}$; (3) Uncertainty $\mathrm{U}_{3}$ caused by the pressure sensor of the instrument; (4) Uncertainty $U_{4}$ caused by modification. The uncertainty of organic heat carrier (Up) was introduced from the above uncertainties, and the extended uncertainty was calculated with a $95 \%$ confidence probability.According to the source of uncertainty, we can calculate the final uncertainty of closed flash point of organic heat carrier.

\subsection{Determination of closed flash point}

Under the condition of repeatability, the closed flash point (after correction) of the organic heat carrier of the same sample was determined, and the average value was calculated as follows:

Table 1. Results of closed flash point

\begin{tabular}{|c|c|}
\hline Times & Result $/{ }^{\circ} \mathbf{C}$ \\
\hline $\mathbf{1}$ & 190.9 \\
\hline $\mathbf{3}$ & 190.2 \\
\hline $\mathbf{4}$ & 191.2 \\
\hline $\mathbf{5}$ & 190.8 \\
\hline $\mathbf{6}$ & 190.1 \\
\hline $\mathbf{7}$ & 190.7 \\
\hline $\mathbf{8}$ & 189.9 \\
\hline Average & 189.8 \\
\hline $\begin{array}{l}\text { Standard } \\
\text { deviation }\end{array}$ & 190.45 \\
\hline
\end{tabular}

The maximum difference of the measured samples was $1.4^{\circ} \mathrm{C}$, in line with the relevant requirements of GB/T 2612008.

\section{Measurement of uncertainty}

\subsection{Uncertainty $U_{1}$ introduced according to repeatability}

The arithmetic mean value of the test results of the closed flash point is $190.45^{\circ} \mathrm{C}$. The uncertainty introduced by the sample repeatability measurement is as follows:

$$
U_{1}=\frac{S(t)}{\sqrt{n}}=\frac{\sqrt{\frac{\sum \triangle(t)^{2}}{n-1}}}{\sqrt{n}}=\frac{0.5155}{\sqrt{8}}=0.1828^{\circ} \mathrm{C}
$$

\subsection{According to the uncertainty $\mathrm{U}_{2}$ introduced by the instrument temperature sensor}

The minimum temperature index of PMA 5 closed flash point meter is $0.1{ }^{\circ} \mathrm{C}$, and the half width of its interval is $0.05{ }^{\circ} \mathrm{C}$. According to the probability distribution is uniform, its confidence factor is, so the uncertainty introduced by the temperature sensor is $U_{2}=\frac{0.05}{\sqrt{3}}=0.029^{\circ} \mathrm{C}$

\subsection{Uncertainty introduced by pressure sensor $U_{3}$}

The minimum pressure index of PMA 5 closed flash point meter is $0.1 \mathrm{kPa}$. According to the standard pressure revision formula, the test data caused by the minimum pressure index is $0.025 \mathrm{kPa}$, and its interval half index is $0.0125 \mathrm{kPa}$. Its confidence factor is, so the uncertainty caused by its pressure sensor is

$$
\mathrm{U}_{3}=\frac{0.0125}{\sqrt{3}}=0.0072^{\circ} \mathrm{C}
$$

\subsection{Uncertainty due to calculation modification $\mathrm{U}_{4}$}

GB/T 261-2008 requires the test result to be accurate to $0.5^{\circ} \mathrm{C}$, and the half-width of the error interval caused by numerical rounding is $0.25{ }^{\circ} \mathrm{C}$. Assuming that its probability distribution is uniform, the confidence factor $\mathrm{k}=\sqrt{3}$ [9]. The measurement uncertainty caused by the rounding of values according to the standard requirements is:

$$
U_{4}=\frac{0.25}{\sqrt{3}}=0.144^{\circ} \mathrm{C}
$$

\subsection{Total uncertainty}

In summary, the comprehensive uncertainty of the closed flash point is

$$
U_{\mathrm{p}}=\sqrt{\left(\mathrm{U}_{1}\right)^{2}+\left(U_{2}\right)^{2}+\left(U_{3}\right)^{2}+\left(U_{4}\right)^{2}}=0.234^{\circ} \mathrm{C}
$$

Tabe2.Summary of uncertainty components

\begin{tabular}{|c|c|}
\hline $\begin{array}{c}\text { Summary of uncertainty } \\
\text { components }\end{array}$ & Result \\
\hline $\begin{array}{c}\text { introduced according to } \\
\text { repeatability }\end{array}$ & 0.1828 \\
\hline
\end{tabular}




\begin{tabular}{|c|c|}
\hline $\begin{array}{c}\text { the instrument } \\
\text { temperature sensor }\end{array}$ & 0.029 \\
\hline pressure sensor & 0.0072 \\
\hline calculation modification & 0.144 \\
\hline Total uncertainty & 0.234 \\
\hline
\end{tabular}

Under the $95 \%$ confidence probability, its expansion factor $\mathrm{K}=2$, so its expanded uncertainty is $\mathrm{U}=\mathrm{KU}_{\mathrm{P}}=0.468{ }^{\circ} \mathrm{C}$, the uncertainty meets the relevant requirements of the national standard GB/T 261-2008.

\subsection{The closing flash point of organic heat carrier can be expressed as:}

$\mathrm{T}=(190.4 \pm 0.5){ }^{\circ} \mathrm{C}$

(including factor $\mathrm{K}=2$, confidence probability $95 \%$ )

\section{Conclusion}

Various important performance and technical indicators of organic heat carrier. Organic heat carrier with good performance index is very important for the safe operation of heat transfer oil boiler. At the same time, the daily operating procedures of the heat transfer system should be standardized during use, and the organic heat transfer system should be regularly checked during operation. The quality of the heat carrier is monitored to prevent the deterioration of the heat transfer oil and ensure the regular and safe development of the organic heat carrier and its boiler market[10].

In the determination of the closed flash point of organic heat carrier, the uncertainty introduced by repeatability and modification is the largest, so in the test process, attention should be paid to strictly follow the procedures, reduce the error caused by repeatability, and improve the accuracy and accuracy of the experimental data [11].

\section{References}

1. AiguoRen.Analys is on application technology of organic heat carrier.Standards and quality of China Petroleum and chemical industry (2014)

2. Larra.eta, E, Donnelly, etal. A proposed model membrane and test method for microneedle insertion studies. International Journal of Pharmaceutics (2014)

3. Xuliang Wang, Jinghong Zhao, Zongyu Li, etal. Uncertainty Evaluation for the Determination of the Retention Ratio of the Ultrafiltration Membrane by BSA. Acta Metrologica Sinica (2019)

4. Xuliang Wang, Jinghong Zhao, Zongyu Li , etal. Uncertainty Evaluation for Testing Results of Ultrafiltration Membrane Pure Water Permeability. China Measurement \& Test (2018)

5. Meng Zhang, Hui Yu, Xuliang Wang, etal. Research on Zeta potential of ultrafiltration
6. membrane.Jounral of Salt and Chemical Industry (2017)

7. Xianhui Pan, Xiaonan Wang, Yanping Zhang, etal. Research and Application Progress of Reference Materials for Detection of Ultrafiltration Membrane Interception Performance.Membrane Science and Technology (2013)

8. GB/T 261-2008 Determination of flash pointPensky-Martens closed cup method.

9. JJF 1059.1-2012 Evaluation and Expression of Uncertainty in Measurement

10. Hong Liang, Interpretation of GB 23971-2009 organic heat carrier national standard. (2010)

11. Xiaohui Zhang, Yan Luo, Jun Sui, etal. Current Situation of Testing Technology of Ulrtafiltration Membrane Performance Index. Value Engineering (2010) 